\title{
Travel, Treatment Choice, and Survival Among Breast Cancer Patients: A Population-Based Analysis
}

\author{
Colleen F. Longacre, ${ }^{1, *}$ Hannah T. Neprash, ${ }^{1}$ Nathan D. Shippee, ${ }^{1}$ Todd M. Tuttle, ${ }^{2}$ and Beth A. Virnig ${ }^{1}$
}

\begin{abstract}
Background: Travel distance to care facilities may shape urban-rural cancer survival disparities by creating barriers to specific treatments. Guideline-supported treatment options for women with early stage breast cancer involves considerations of breast conservation and travel burden: Mastectomy requires travel for surgery, whereas breast-conserving surgery (BCS) with adjuvant radiation therapy (RT) requires travel for both surgery and RT. This provides a unique opportunity to evaluate the impact of travel distance on surgical decisions and receipt of guideline-concordant treatment.

Materials and Methods: We included 61,169 women diagnosed with early stage breast cancer between 2004 and 2013 from the Surveillance Epidemiology and End Results (SEER)-Medicare database. Driving distances to the nearest radiation facility were calculated by using Google Maps. We used multivariable regression to model treatment choice as a function of distance to radiation and Cox regression to model survival.

Results: Women living farthest from radiation facilities ( $>50$ miles vs. $<10$ miles) were more likely to undergo mastectomy versus BCS (odds ratio [OR]: 1.48, 95\% confidence interval [Cl]: 1.22-1.79). Among only those who underwent BCS, women living farther from radiation facilities were less likely to receive guidelineconcordant RT (OR: 1.72, 95\% Cl: 1.32-2.23). These guideline-discordant women had worse overall (hazards ratio [HR]: $1.50,95 \% \mathrm{Cl}: 1.42-1.57)$ and breast-cancer specific survival (HR: 1.44, 95\% Cl: 1.29-1.60).

Conclusions: We report two breast cancer treatments with different clinical and travel implications to show the association between travel distance, treatment decisions, and receipt of guideline-concordant treatment. Differential access to guideline-concordant treatment resulting from excess travel burden among rural patients may contribute to rural-urban survival disparities among cancer patients.
\end{abstract}

Keywords: breast cancer; patient decision making; radiation treatment; travel distance

\section{Introduction}

Survival disparities persist between rural and urban cancer patients. ${ }^{1}$ Travel distance to care facilities may contribute to these disparities by creating barriers to accessing specific treatments; however, it is often difficult to disentangle factors impacting patient treatment choices. Women diagnosed with early stage breast cancer have two guideline-supported treatment options:
(1) mastectomy and (2) breast-conserving surgery (BCS) followed by radiation therapy (RT). ${ }^{2-4}$ Although overall survival between the two choices is equivalent, BCS+RT is the preferred strategy of the majority of eligible patients ${ }^{5}$ likely because it has been associated with lower complications and $\operatorname{costs}^{6}$ and superior quality of life relative to mastectomy. ${ }^{7}$ However, $\sim 15 \%-30 \%$ of patients who undergo BCS do not

${ }^{1}$ Division of Health Policy and Management, University of Minnesota School of Public Health, Minneapolis, Minnesota, USA.

${ }^{2}$ Department of Surgery, University of Minnesota Medical School, Minneapolis, Minnesota, USA.

*Address correspondence to: Colleen F. Longacre, PhD, MPH, Division of Health Policy and Management, University of Minnesota School of Public Health, 420 Delaware Ave SE, Minneapolis, MN 55454, USA, E-mail: longa020@umn.edu

(c) Colleen F. Longacre et al., 2021; Published by Mary Ann Liebert, Inc. This Open Access article is distributed under the terms of the Creative Commons License (http://creativecommons.org/licenses/by/4.0), which permits unrestricted use, distribution, and reproduction in any medium, provided the original work is properly cited. 
receive recommended $\mathrm{RT}^{5,8-10}$ Disparities in $\mathrm{RT}$ completion have been associated with age, race, and geography ${ }^{5}$ and have been linked to poorer diseasespecific outcomes and overall survival. ${ }^{11,12}$ Little is known about how prevalent incomplete RT (receipt of some RT but not the full recommended course) is among early stage breast cancer patients, although this has also been associated with poorer patient outcomes in some studies. ${ }^{11,13}$ Distance may play a significant role in patient decision making regarding surgery and completion of RT, since RT requires daily travel to radiation facilities for several weeks at a time. The combination of two clinically comparable treatment options with different travel implications provides a unique opportunity to evaluate the impact of travel distance on care decisions and receipt of guidelineconcordant treatment.

Available evidence from mostly state-level studies suggests that patients who live farther from radiation facilities may be more likely to choose mastectomy ${ }^{14-22}$ or to not complete recommended radiation after BCS. ${ }^{14,17,21-23}$ In this study, we evaluate the association between travel distance and choice of surgical treatment (mastectomy vs. BCS) and optimal receipt of radiation after BCS among newly diagnosed breast cancer patients in the Medicare population. We then explore the relationship between travel distance, optimal treatment receipt, and survival outcomes.

\section{Materials and Methods}

Data

Data for this study came from the National Cancer Institute (NCI)'s linked Surveillance Epidemiology and End Results (SEER)-Medicare database. ${ }^{24}$ The SEER cancer registries provide population-based cancer surveillance for 18 areas that represent $\sim 30 \%$ of the United States. ${ }^{25}$ The SEER-Medicare database combines information from the SEER cancer registries with Medicare claims and enrollment data. The combined data include detailed clinical information about the tumors, demographic characteristics, information on cause of death, and Medicare claims for covered health care services from the time of a person's Medicare eligibility. ${ }^{24}$

\section{Patients}

The study cohort included women age 65 and older diagnosed with stage I or 2 first primary breast cancer between 2004 and 2013 who were enrolled in fee-forservice (FFS) Medicare for at least 12 months before and after diagnosis and underwent surgery (mastectomy or BCS) as part of their initial treatment. We excluded patients 85 years and older, those with atypical histologies, and those diagnosed via death certificate or autopsy. We excluded patients whose Medicare ZIP code did not coincide with their SEER registry state, those with unknown ZIP codes, and those for whom driving distances could not be calculated (Supplementary Appendix Table SA1).

\section{Definition and measurement of key variables}

Patient-level demographic variables obtained from Medicare included patient age, race, marital status, dual Medicare-Medicaid eligibility status, and level of comorbidity. Patient-level tumor characteristics obtained from SEER included disease stage, grade, regional node involvement, and hormone receptor status. ZIP-code level demographic variables included median household income and level of rurality. Comorbidity was calculated by using the Charlson Comorbidity Score (NCI 2014 version), ${ }^{26}$ categorized into $0,1,2$, and 3+. Median household income was categorized into approximate quartiles of $<\$ 45,000, \$ 45,000$ $60,000, \$ 60,000-75,000$, and $>\$ 75,000$. For all demographic and disease variables, missing values were dummy coded into their own category.

Type of surgery, delivery of radiation treatment, and the type of radiation treatment were identified by the relevant Current Procedural Terminology codes $^{27}$ in the patient Medicare claims (Supplementary Appendix Table SA2). We restricted our analysis of radiation completeness to patients who had conventional radiotherapy, intensity-modulated radiation therapy (IMRT), a combination of conventional and IMRT, or brachytherapy. We excluded patients who had alternative forms of radiation (stereotactic body radiation treatment, proton beam radiation, neutron beam radiation, and electronic brachytherapy), and those for whom type of radiation treatment received could not be distinguished from their claims. Incomplete radiation was defined as patients who received less than $15 \mathrm{U}$ of conventional radiotherapy or IMRT. This is a fairly conservative estimate of completion compared with other studies ${ }^{2-4,28}$ and reflects the evolving understanding of the effectiveness of shorter-course regimens, ${ }^{29}$ allowing these courses to be considered complete. Patients with less than $15 \mathrm{U}$ of radiotherapy who died within 60 days of their last documented radiation treatment were not considered to have received an incomplete course of radiation. 


\section{Identification of radiation treatment facilities}

Among patients who received radiation, we determined the location where radiation treatment occurred by the claim service facility ZIP code if the radiation claim came from the outpatient file and the provider ZIP code if the radiation claim came from the carrier file. We defined available radiation treatment facilities as radiation facilities where at least one patient in our cohort received radiation treatment.

\section{Distance calculations}

Minimum travel distance was defined as the driving distance between the centroid of the patient's ZIP code and the centroid of the ZIP code of the nearest available facility. The nearest available facility was determined by using the Network Analyst extension of ArcGIS Pro 10.6.1, ${ }^{30}$ and driving distances were calculated by using the Google Maps Distance Matrix Application Programming Interface (API) ${ }^{31}$ Distance to the nearest available radiation facility was categorized into four groups $(<10$, $10-25,25-50$, and $>50$ miles).

\section{Statistical analyses}

Treatment decision model: In our statistical models, we estimated the association between: (1) distance to radiation facilities and surgical choice (mastectomy vs. BCS); and (2) distance to radiation facilities and receipt of RT among patients receiving BCS. For the model of radiation receipt after $\mathrm{BCS}$, those defined as having incomplete radiation were included in the BCS + RT category, due to sample size constraints and to provide a more conservative estimate of nonreceipt. We also estimated a model comparing those who received incomplete radiation with those receiving a complete course of radiation. All models controlled for patient age, race, marital status, year of diagnosis, county-level household income, dual Medicare-Medicaid eligibility, level of co-morbidity, tumor grade, hormone receptor status, regional node involvement, and SEER registry. To account for geographic variation in mastectomy rates, ${ }^{32}$ standard errors were clustered at the state level. We considered three alternative discrete choice models: (1) two independent logit models, (2) a multinomial logit model, and (3) a bivariate probit model with sample selection. Each of these three specifications makes different assumptions about the relationship between these treatment decisions. ${ }^{33-35}$

Some recent evidence suggests that RT after BCS may not be necessary for certain patients in our study cohort (women aged 70 and above with stage 1 ,
ER+ tumors). ${ }^{36,37}$ As a sensitivity analysis, we eliminated such patients from our analysis of radiation receipt after BCS. As an additional sensitivity analysis, we added a provider fixed effect for the facility where the patient underwent surgery.

\section{Survival analysis}

To understand the survival implications of both travel distance and receipt of guideline-concordant treatment, we used a Cox proportional hazards model to evaluate whether there were survival differences associated with travel distance as well as receipt of guidelineconcordant treatment (mastectomy or BCS+RT) versus guideline-discordant treatment (BCS without RT) in our study population.

We used SAS software, version 9.1.4 (SAS Institute, Inc., Cary, NC, USA) for all analyses, and we considered $p<0.05$ to be statistically significant. The study was reviewed by the Institutional Review Board (IRB) of the University of Minnesota who determined the study was exempt from full review.

\section{Results}

We identified 61,169 patients who met our inclusion criteria (Table 1). We found that $32 \%$ of patients were treated with mastectomy, 54\% were treated with $\mathrm{BCS}+\mathrm{RT}, 12 \%$ were treated with BCS without RT, and $2 \%$ were treated with BCS plus incomplete RT. Three-quarters $(75 \%)$ of patients lived within 10 miles of a radiation facility, whereas $10 \%$ lived at least 25 miles from a radiation facility.

Among radiation patients, $73 \%$ received conventional radiotherapy, $12 \%$ received a combination of conventional radiotherapy plus IMRT, 9\% received brachytherapy, and $4 \%$ received IMRT only. Only $0.4 \%$ of patients received an alternative type of radiation, and type of radiation could not be distinguished for $0.8 \%$ of patients. Frequency of radiation treatment type remained fairly stable over time, with a slight decrease in conventional radiotherapy and a slight increase in conventional radiotherapy plus IMRT or IMRT only. The median conventional radiotherapy patient received 33 radiation treatment units over a period of 50 days, whereas the median brachytherapy patient received 15 radiation treatment units over a period of 8 days (see Supplementary Appendix Table SA3 for full results).

\section{Treatment model results}

Table 2 presents the results of the multivariate logistic regression models. We found our results to be robust to 
Table 1. Baseline Patient Demographic and Disease Characteristics

\begin{tabular}{|c|c|c|c|c|c|c|c|c|}
\hline \multirow[b]{3}{*}{ Characteristic } & \multicolumn{8}{|c|}{$\begin{array}{l}\text { Distance to the nearest available } \\
\text { radiation facility }\end{array}$} \\
\hline & \multicolumn{2}{|c|}{$\begin{array}{l}<10 \\
\text { miles }\end{array}$} & \multicolumn{2}{|c|}{$\begin{array}{l}10-25 \\
\text { miles }\end{array}$} & \multicolumn{2}{|c|}{$\begin{array}{l}25-50 \\
\text { miles }\end{array}$} & \multicolumn{2}{|c|}{$\begin{array}{l}>50 \\
\text { miles }\end{array}$} \\
\hline & $N$ & $\%$ & $N$ & $\%$ & $N$ & $\%$ & $N$ & $\%$ \\
\hline & 45,632 & & 9,730 & & 4,786 & & 1,021 & \\
\hline \multicolumn{9}{|l|}{ Treatment } \\
\hline Mastectomy & 13,630 & 30 & 3,357 & 35 & 2,216 & 46 & 456 & 45 \\
\hline $\mathrm{BCS}$ + radiation & 25,700 & 56 & 5,093 & 52 & 2,002 & 42 & 400 & 39 \\
\hline $\mathrm{BCS}+$ no radiation & 5,396 & 12 & 1,112 & 11 & 502 & 10 & 142 & 14 \\
\hline $\begin{array}{l}\mathrm{BCS}+\text { incomplete } \\
\text { radiation }\end{array}$ & 906 & 2 & 168 & 2 & 66 & 1 & 23 & 2 \\
\hline \multicolumn{9}{|l|}{ Age at diagnosis } \\
\hline $65-69$ & 13,144 & 29 & 3,090 & 32 & 1,416 & 30 & 305 & 30 \\
\hline $70-74$ & 12,847 & 28 & 2,843 & 29 & 1,383 & 29 & 312 & 31 \\
\hline $75-79$ & 11,162 & 24 & 2,264 & 23 & 1,196 & 25 & 226 & 22 \\
\hline $80-84$ & 8,479 & 19 & 1,533 & 16 & 791 & 17 & 178 & 17 \\
\hline \multicolumn{9}{|l|}{ Race } \\
\hline White & 38,778 & 85 & 8,907 & 92 & 4,390 & 92 & 940 & 92 \\
\hline Black & 3,659 & 8 & 434 & 4 & 311 & 6 & 25 & 2 \\
\hline Other & 3,195 & 7 & 389 & 4 & 85 & 2 & 56 & 5 \\
\hline \multicolumn{9}{|l|}{ Marital status } \\
\hline $\begin{array}{l}\text { Single (never married, } \\
\text { unmarried, } \\
\text { separated, divorced) }\end{array}$ & 8,219 & 18 & 1,285 & 13 & 617 & 13 & 156 & 15 \\
\hline Married & 22,009 & 48 & 5,238 & 54 & 2,462 & 51 & 532 & 52 \\
\hline Widowed & 13,636 & 30 & 2,818 & 29 & 1,570 & 33 & 270 & 26 \\
\hline Unknown & 1,768 & 4 & 1,768 & 18 & 137 & 3 & 63 & 6 \\
\hline \multicolumn{9}{|l|}{ Medicaid dual status } \\
\hline Yes & 6,013 & 13 & 1,206 & 12 & 784 & 16 & 146 & 14 \\
\hline No & 39,619 & 87 & 8,524 & 88 & 4,002 & 84 & 875 & 86 \\
\hline \multicolumn{9}{|l|}{ Disease stage } \\
\hline 1 & 29,692 & 65 & 6,324 & 65 & 3,042 & 64 & 590 & 58 \\
\hline 2 & 15,940 & 35 & 3,406 & 35 & 1,744 & 36 & 431 & 42 \\
\hline \multicolumn{9}{|l|}{ Grade } \\
\hline 1 & 12,139 & 27 & 2,703 & 28 & 1,303 & 27 & 276 & 27 \\
\hline 2 & 20,404 & 45 & 4,183 & 43 & 2,052 & 43 & 435 & 43 \\
\hline $3+$ & 11,516 & 25 & 2,538 & 26 & 1,279 & 27 & 271 & 27 \\
\hline Unknown & 1,573 & 3 & 306 & 3 & 152 & 3 & 39 & 4 \\
\hline \multicolumn{9}{|l|}{ Regional node positivity } \\
\hline No nodes positive & 34,425 & 75 & 7,413 & 76 & 3,573 & 75 & 748 & 73 \\
\hline Any nodes positive & 7,960 & 17 & 1,691 & 17 & 862 & 18 & 190 & 19 \\
\hline No nodes tested & 3,247 & 7 & 3,247 & 33 & 351 & 7 & 83 & 8 \\
\hline \multicolumn{9}{|l|}{ ER status } \\
\hline Positive & 37,537 & 82 & 7,850 & 81 & 3,842 & 80 & 814 & 80 \\
\hline Negative & 6,427 & 14 & 1,423 & 15 & 704 & 15 & 149 & 15 \\
\hline Borderline/unknown & 1,668 & 4 & 457 & 5 & 240 & 5 & 58 & 6 \\
\hline \multicolumn{9}{|c|}{ Charlson Comorbidity Score } \\
\hline 0 & 26,809 & 59 & 5,787 & 59 & 2,800 & 59 & 605 & 59 \\
\hline 1 & 10,662 & 23 & 2,322 & 24 & 1,111 & 23 & 253 & 25 \\
\hline 2 & 4,144 & 9 & 841 & 9 & 442 & 9 & 83 & 8 \\
\hline $3+$ & 3,268 & 7 & 657 & 7 & 380 & 8 & 67 & 7 \\
\hline Unknown & 749 & 2 & 123 & 1 & 53 & 1 & 13 & 1 \\
\hline
\end{tabular}

$\mathrm{BCS}$, breast-conserving surgery.

treatment model specification-coefficient estimates across the three models did not differ appreciably in either magnitude or direction. For simplicity and ease of comparison with other studies, we report the results of the two independent logit models throughout the re- mainder of the article. Coefficient estimates for each of the three models are reported in Supplementary Appendix Table SA4. Increased distance to the nearest radiation facility was associated with increasing odds of mastectomy $(p<0.001)$. Compared with living within 10 miles of a radiation facility, living 10-25 miles away increased the odds of mastectomy by $6 \%$ (odds ratio [OR]: 1.06, 95\% confidence interval [CI]: 1.01-1.13), whereas living 25-50 miles away increased the odds of mastectomy by $43 \%$ (OR: 1.43 , 95\% CI: $1.30-1.57$ ), and living $>50$ miles away increased the odds of mastectomy by $48 \%$ (OR: $1.48,95 \%$ CI: $1.22-1.79$ ). Other factors significantly associated with increased odds of mastectomy included older age, Other race, being single or widowed, Medicaid dual status, higher levels of comorbidity, higher stage and higher grade tumors, and negative or borderline/unknown ER status. No lymph node testing and higher median household income were associated with decreased odds of mastectomy. Adding a provider fixed effect does somewhat attenuate the association between distance and treatment decisions, but the associations remain significant, particularly among patients living $>25$ miles from the nearest radiation facility (Supplementary Appendix Table SA5).

Similarly, increased distance to the nearest radiation facility was associated with increasing odds that a BCS patient would not receive RT $(p<0.001)$. Compared with living within 10 miles of a radiation facility, living 10-25 miles away increased the odds of no radiation by 9\% (OR: 1.09, 95\% CI: 0.99-1.19), whereas living 25-50 miles away increased the odds of no radiation by $23 \%$ (OR: 1.23, 95\% CI: 1.07-1.41), and living $>50$ miles away increased the odds of no radiation by $72 \%$ (OR: 1.72, 95\% CI: 1.32-2.23).

Other factors significantly associated with increased odds of failing to receive RT after BCS included older age, Black race, being single or widowed, Medicaid dual status, higher levels of comorbidity, not receiving lymph node testing, and borderline/unknown ER status. The combination of no lymph node testing and unknown ER status suggests that not receiving RT is associated with those receiving less comprehensive care overall. Other race, higher grade and ER-tumors, and lymph node positivity were associated with decreased odds of not receiving RT. Although higher median household income was significantly associated with lower mastectomy rates, it was not associated with rates of RT completion. Restricting our sample to those who would not be eligible for BCS without RT under current guidelines did not impact the results. 
Table 2. Odds Ratio Estimates of Selected Characteristics on Treatment Decisions

\begin{tabular}{|c|c|c|c|c|c|c|c|c|c|c|c|c|}
\hline & \multicolumn{4}{|c|}{$\begin{array}{c}\text { Odds of mastectomy } \\
\text { versus BCS }\end{array}$} & \multicolumn{4}{|c|}{$\begin{array}{l}\text { Odds of no RT versus } \\
\text { any RT after BCS }\end{array}$} & \multicolumn{4}{|c|}{$\begin{array}{l}\text { Odds of incomplete RT versus } \\
\text { complete RT after BCS }\end{array}$} \\
\hline & $\mathrm{OR}^{\mathrm{b}}$ & \multicolumn{2}{|c|}{$95 \% \mathrm{Cl}$} & $p^{c}$ & $\mathrm{OR}^{\mathrm{b}}$ & \multicolumn{2}{|c|}{$95 \% \mathrm{Cl}$} & $p^{c}$ & $\mathrm{OR}^{\mathrm{b}}$ & \multicolumn{2}{|c|}{$95 \% \mathrm{Cl}$} & $p^{c}$ \\
\hline \multicolumn{13}{|c|}{ Distance to nearest radiation facility } \\
\hline$<10$ miles & REF & & & $<0.0001$ & REF & & & $<0.0001$ & REF & & & 0.00 \\
\hline 10-25 miles & 1.06 & 0.97 & 1.17 & & 1.09 & 1.01 & 1.16 & & 0.89 & 0.68 & 1.16 & \\
\hline 25-50 miles & 1.43 & 1.23 & 1.67 & & 1.23 & 1.08 & 1.39 & & 1.15 & 0.84 & 1.57 & \\
\hline$>50$ miles & 1.48 & 1.17 & 1.86 & & 1.72 & 1.37 & 2.15 & & 1.79 & 1.24 & 2.60 & \\
\hline \multicolumn{13}{|l|}{ Age at diagnosis } \\
\hline $65-69$ & REF & & & $<0.0001$ & REF & & & $<0.0001$ & REF & & & $<0.0001$ \\
\hline $70-74$ & 1.07 & 1.00 & 1.14 & & 1.23 & 1.15 & 1.33 & & 1.10 & 0.94 & 1.28 & \\
\hline $75-79$ & 1.13 & 1.04 & 1.22 & & 1.79 & 1.69 & 1.90 & & 1.01 & 0.87 & 1.17 & \\
\hline $80-84$ & 1.30 & 1.18 & 1.43 & & 3.12 & 2.76 & 3.53 & & 1.35 & 1.14 & 1.59 & \\
\hline \multicolumn{13}{|l|}{ Race } \\
\hline White & REF & & & $<0.0001$ & REF & & & $<0.0001$ & REF & & & 0.36 \\
\hline Black & 0.96 & 0.87 & 1.05 & & 1.27 & 1.14 & 1.41 & & 1.18 & 0.82 & 1.70 & \\
\hline Other & 1.56 & 1.40 & 1.73 & & 0.88 & 0.75 & 1.02 & & 0.93 & 0.74 & 1.17 & \\
\hline \multicolumn{13}{|l|}{ Marital status } \\
\hline Married & REF & & & $<0.0001$ & REF & & & $<0.0001$ & REF & & & 0.01 \\
\hline Single & 1.12 & 1.07 & 1.18 & & 1.23 & 1.12 & 1.35 & & 0.95 & 0.82 & 1.11 & \\
\hline Widowed & 1.15 & 1.11 & 1.20 & & 1.17 & 1.10 & 1.25 & & 0.93 & 0.82 & 1.05 & \\
\hline Unknown & 1.12 & 1.04 & 1.73 & & 1.37 & 1.07 & 1.75 & & 1.50 & 1.01 & 2.20 & \\
\hline \multicolumn{13}{|l|}{ Medicaid dual status } \\
\hline No & REF & & & $<0.0001$ & REF & & & $<0.0001$ & REF & & & 0.43 \\
\hline Yes & 1.44 & 1.39 & 1.49 & & 1.36 & 1.23 & 1.50 & & 1.08 & 0.89 & 1.31 & \\
\hline \multicolumn{13}{|c|}{ Charlson Comorbidity Score } \\
\hline 0 & REF & & & $<0.0001$ & REF & & & $<0.0001$ & REF & & & 0.15 \\
\hline 1 & 1.09 & 1.03 & 1.15 & & 1.03 & 0.95 & 1.12 & & 1.00 & 0.88 & 1.13 & \\
\hline 2 & 1.18 & 1.13 & 1.24 & & 1.27 & 1.18 & 1.36 & & 1.15 & 0.97 & 1.37 & \\
\hline $3+$ & 1.34 & 1.25 & 1.43 & & 1.43 & 1.33 & 1.54 & & 1.13 & 0.96 & 1.32 & \\
\hline \multicolumn{13}{|l|}{ Stage } \\
\hline 1 & REF & & & $<0.0001$ & REF & & & 0.06 & REF & & & 0.04 \\
\hline 2 & 2.48 & 2.34 & 2.63 & & 1.08 & 1.00 & 1.17 & & 0.86 & 0.75 & 0.99 & \\
\hline \multicolumn{13}{|l|}{ Grade } \\
\hline 1 & REF & & & $<0.0001$ & REF & & & $<0.0001$ & REF & & & 0.05 \\
\hline 2 & 1.23 & 1.16 & 1.30 & & 0.79 & 0.74 & 0.85 & & 0.86 & 0.75 & 0.99 & \\
\hline $3+$ & 1.42 & 1.34 & 1.49 & & 0.73 & 0.66 & 0.80 & & 0.83 & 0.67 & 1.02 & \\
\hline Unknown & 1.48 & 1.38 & 1.58 & & 0.96 & 0.81 & 1.13 & & 0.82 & 0.57 & 1.19 & \\
\hline \multicolumn{13}{|l|}{ Regional node positivity } \\
\hline No nodes positive & REF & & & $<0.0001$ & REF & & & $<0.0001$ & REF & & & 0.00 \\
\hline Any nodes positive & 1.04 & 0.98 & 1.10 & & 0.76 & 0.62 & 0.93 & & 0.88 & 0.68 & 1.14 & \\
\hline No nodes tested & 0.34 & 0.30 & 0.38 & & 4.47 & 4.16 & 4.80 & & 1.18 & 1.01 & 1.37 & \\
\hline \multicolumn{13}{|l|}{ ER status } \\
\hline Positive & REF & & & $<0.0001$ & REF & & & $<0.0001$ & REF & & & 0.32 \\
\hline Negative & 1.21 & 1.15 & 1.28 & & 0.89 & 0.80 & 0.99 & & 1.07 & 0.89 & 1.28 & \\
\hline Borderline/unknown & 1.63 & 1.43 & 1.85 & & 1.46 & 1.15 & 1.85 & & 0.86 & 0.49 & 1.53 & \\
\hline \multicolumn{13}{|c|}{ Median household income percentile } \\
\hline$<\$ 45,000$ & REF & & & 0.00 & REF & & & 0.37 & REF & & & 0.61 \\
\hline$\$ 45,000-60,000$ & 0.93 & 0.85 & 1.01 & & 0.97 & 0.90 & 1.04 & & 1.02 & 0.85 & 1.21 & \\
\hline$\$ 60,000-75,000$ & 0.92 & 0.85 & 0.99 & & 0.99 & 0.94 & 1.04 & & 0.96 & 0.67 & 1.38 & \\
\hline$>\$ 75,000$ & 0.85 & 0.78 & 0.92 & & 0.90 & 0.79 & 1.02 & & 0.83 & 0.57 & 1.21 & \\
\hline
\end{tabular}

Models also control for year of diagnosis and SEER registry from which the data were obtained.

an this model, BCS+RT includes both complete and incomplete radiation.

${ }^{\mathrm{b}} \mathrm{ORs}>1$ are interpreted as increasing odds of mastectomy (model 1), increasing odds that a BCS patient did not receive RT (model 2 ), and increasing odds that a BCS patient received incomplete RT (model 3).

'Global $p$-values calculated by using a Type 3 Wald test.

$\mathrm{Cl}$, confidence interval; OR, odds ratio; RT, radiation therapy; SEER, Surveillance Epidemiology and End Results. 
Living $>50$ miles from the nearest radiation facility was also associated with increasing odds of receiving an incomplete course of RT $(\mathrm{OR}=1.79,95 \% \mathrm{CI}$ : 1.24-2.60), though this association was not observed at distances of $10-25$ or $25-50$ miles. Age $80-84$ years, unknown marital status, and not receiving lymph node testing were significantly associated with receiving an incomplete course of radiation. Stage 2 patients were less likely to receive an incomplete course of radiation than stage 1 patients.

\section{Survival analysis}

Supplementary Appendix Figure SA1 shows the unadjusted relationship between patient travel distance to the nearest radiation facility and survival. Patients living $>50$ miles from a radiation facility experienced worse survival outcomes compared with patients living $<10$ miles from a radiation facility $(p<0.001)$. In our multivariable Cox model, this association between patient travel distance and survival is no longer significant. However, in this model, patients receiving guideline-discordant care (BCS without RT) had significantly worse overall (HR: 1.50, 95\% CI: 1.42-1.57) and breast-cancer specific survival (HR: 1.44, 95\% CI: 1.291.60) than those receiving guideline-concordant treatment (Table 3).

\section{Discussion}

Our results strongly suggest that the distance breast cancer patients must travel to access radiation is associated with both their surgical treatment decision (mastectomy vs. BCS) and their decision to receive recommended radiation after BCS. These findings build on previous studies ${ }^{14-21,23,38,39}$ and add to a growing body of research that recognizes patient travel distance as an important barrier to access in cancer care, particularly among older and more vulnerable populations. ${ }^{40-42}$ Our study also helps to illustrate the mechanism through which observed rural-urban survival disparities may occur-patients living farther from treatment facilities are more likely to receive guideline-discordant treatment, and those receiving guideline-discordant treatment experience worse survival outcomes. ${ }^{43}$

Our study used strong data and innovative methods to improve on previous research in several ways. Using SEER-Medicare linked claims data, we were able to verify patient receipt of RT. To our knowledge, ours is the first study to attempt to characterize and quantify incomplete RT in a population-based study. Our sample included a large and diverse population of Medicare patients across 12 states. We also employed more recently available and sophisticated measures of calculating travel distance that allowed us to compute actual driving distances, rather than rely on great circle or "as the crow flies" measures of distance. Our findings were robust to various specifications of the treatment decision model. This strengthens our confidence in the observed association between travel distance and treatment decisions as well as the findings of previous studies that did not consider alternative model specifications.

In our patient cohort, $12 \%$ of patients were treated with BCS without RT and $2 \%$ of patients were treated with incomplete RT. This means that $14 \%$ of all patients and $20 \%$ of BCS patients in this cohort received guideline-discordant care. The proportion of patients receiving guideline-discordant care is similar to those reported in previous studies. ${ }^{5,8-10}$ Our findings suggest that patients receiving incomplete RT make up only a small percentage of breast cancer patients, and that the majority $(86 \%)$ of patients receiving guidelinediscordant care are not receiving any RT. However, those patients living more than 50 miles from a radiation facility are more likely to have incomplete courses of radiation. Using Medicare claims also allowed us to identify the type of radiation patients received. Among RT patients in our cohort, most (91\%) received conventional radiotherapy, IMRT, or a combination of the two. Only 9\% of patients in our study cohort received brachytherapy; this proportion is similar to other studies of brachytherapy use in the Medicare population. $^{44}$

Although there is ample literature on patient autonomy and shared decision making in breast cancer treatment, ${ }^{45-50}$ the question of whether surgical and radiation decisions are considered separately or in tandem has not been addressed. Numerous decision aids for breast cancer surgical decision making have been developed and tested, ${ }^{51,52}$ whereas a few decision aids exist to assist patients and physicians with radiotherapy decision making. ${ }^{45,53}$

Understanding how clinicians and patients can improve adherence to guideline-concordant treatment is particularly important, given that in our study we continue to see survival differences between those who receive guideline-concordant treatment and those who do not. Existing evidence suggests that surgeon participation in the radiation decision may lead to more guideline-concordant care $^{54}$ but that many 
Table 3. Cox Proportional Hazards Models of Overall and Breast Cancer-Specific 10-Year Survival

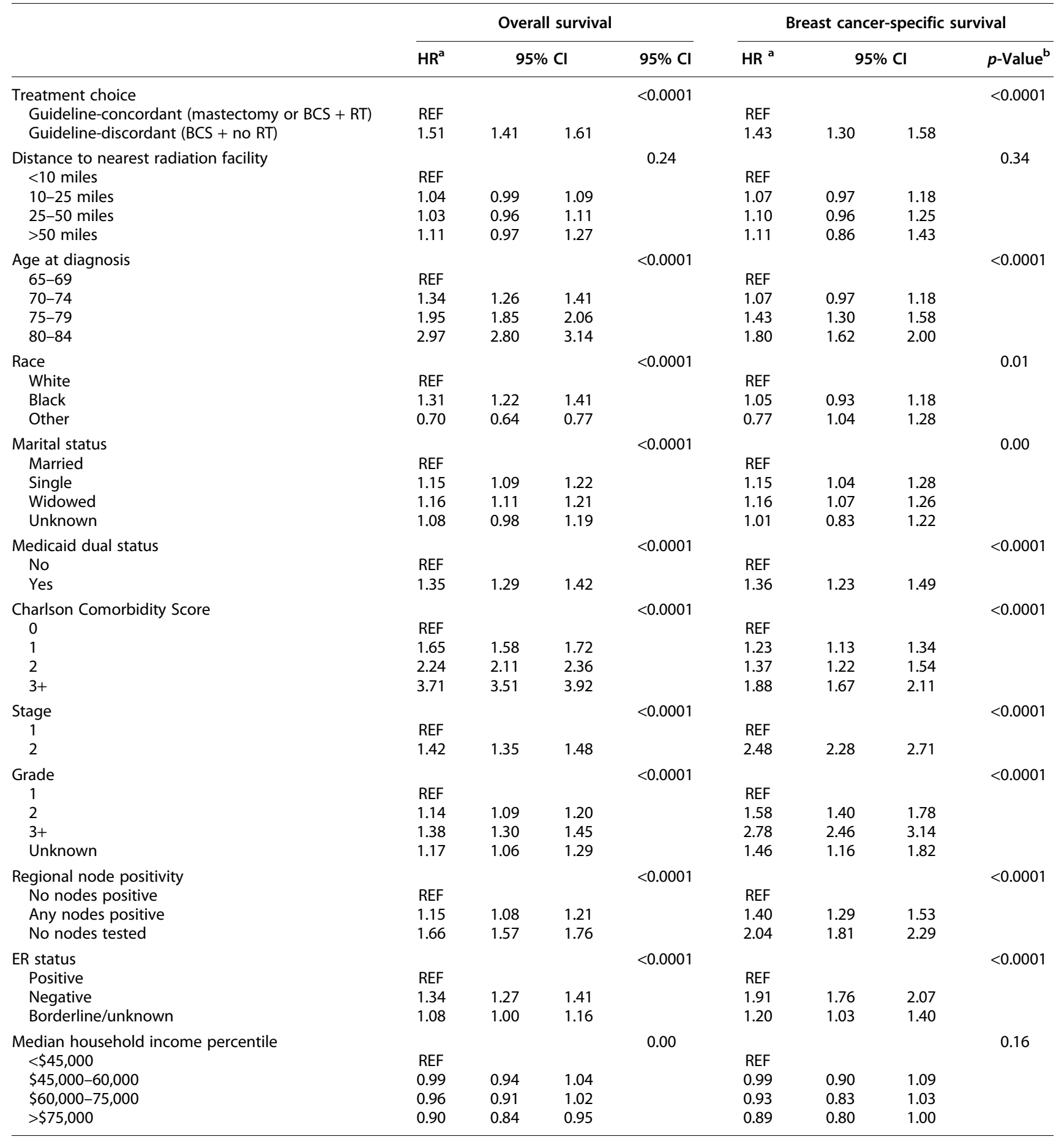

Models also control for year of diagnosis and SEER registry from which the data were obtained.

${ }^{a} \mathrm{HRs}>1$ are interpreted as increasing odds of death.

${ }^{\mathrm{b}} \mathrm{Global} p$-values calculated by using a Type 3 Wald test.

$\mathrm{HR}$, hazards ratio. 
surgeons may have inadequate knowledge of the role of radiation in proper breast cancer management. ${ }^{55}$

Adoption of shorter course radiation treatment regimens is a strategy that could both reduce travel burden and improve treatment adherence among breast cancer patients. Despite the establishment of noninferiority of shorter course hypofractionated $\mathrm{RT}^{13,56,57}$ and its recommendation for use among older breast cancer patients, ${ }^{57}$ uptake of this regimen in the United States has been slow. ${ }^{58}$ Similarly, omission of radiation after BCS for eligible elderly breast cancer patients has also been slow to disseminate after the release of updated guidelines. ${ }^{59,60}$ Provider-side financial incentives in FFS Medicare, in which additional fractions are tied to additional reimbursement, may be driving this slow uptake. ${ }^{58,61}$ Adoption of value-based payment models could help accelerate adoption.

Although brachytherapy in older breast cancer patients has been associated with a higher risk of complications and subsequent mastectomy compared with conventional radiotherapy, ${ }^{44}$ brachytherapy does significantly reduce the median time period over which radiation treatment occurs (from 50 to 8 days in our study cohort), and it may be an attractive alternative for patients for whom travel burden is the primary barrier to completing RT. Ongoing clinical trial research ${ }^{62}$ suggests that safer, more effective brachytherapy techniques may present an alternative treatment option for elderly breast cancer patients in future.

Apart from modifying treatment regimens, clinicians and policymakers should explore service delivery and social support models that reduce travel burden among breast cancer patients and thereby reduce its salience on their treatment decisions. Lodging, ${ }^{63}$ transportation support, ${ }^{64,65}$ and transportation reimbursement ${ }^{66}$ models could be adapted or expanded.

This study has several limitations. First, our study cohort is restricted to women age 65 and over enrolled in FFS Medicare; therefore, the results may not be generalizable to younger women or those enrolled in Medicare Advantage plans. An important strength of using FFS Medicare data is that it precludes the potential confounding effect of insurance status. Because virtually every provider accepts FFS Medicare, we can say with some certainty that if a radiation facility or reconstruction provider exists in a geographic area covered by the SEER program, a patient in our study cohort would have coverage to use it. This would not necessarily be true among commercially insured patients, for whom network participation would be a major consid- eration. Second, our measure of available radiation facilities relies on observation of the facility in the SEER-Medicare claims data. This may lead us to either overestimate or underestimate distance to the nearest available facility. Distance to the nearest available facility would be overestimated if the nearest available facility to a patient was not visited by any other patient in our cohort. To minimize this risk, we excluded patients coming from non-SEER registry states. Distance to the nearest available facility would be underestimated if we included in our analysis a facility that is not actually providing radiation treatment services; for example, if the zip code on the claim was not the actual zip code where the treatment was provided or if a satellite radiation facility billed through a centralized health care system billing address.

In the event that this occurred, our analysis would provide a conservative estimate of distance to the nearest available facility. Third, we do not consider the availability of other providers, such as plastic surgeons able to perform breast reconstruction, which may affect a patient's decision of whether or not to undergo a mastectomy. In spite of these limitations, our study contributes valuable new information on the role of patient travel distance on treatment decisions and outcomes among older breast cancer patients across the United States.

\section{Conclusion}

Travel distance to radiation facilities is associated with both the choice of surgical treatment and the decision of whether to undergo RT among breast cancer patients in the Medicare population. Patients living farther from radiation facilities were more likely to be treated with mastectomy compared with BCS and less likely to complete recommended RT after BCS. Patients treated with BCS without RT experienced worse breast-cancer specific and overall survival outcomes compared with patients treated with guidelineconcordant treatment (mastectomy or BCS+RT). Thus, rural-urban survival disparities among cancer patients may be, in part, attributable to differential access to guideline-concordant treatment resulting from excess travel burden among rural patients. Clinicians, policymakers, and patient advocates should explore social support and service delivery models at reducing travel burden and improving guideline-concordant treatment among this patient population.

\section{Author Disclosure Statement}

No competing financial interests exist. 


\section{Funding Information}

This research received funding from the Agency for Healthcare Research and Quality through an R36 dissertation grant (No. 1R36HS026660-01).

\section{Supplementary Data}

Supplementary Appendix Figure SA1

Supplementary Appendix Table SA1

Supplementary Appendix Table SA2

Supplementary Appendix Table SA3

Supplementary Appendix Table SA4

Supplementary Appendix Table SA5

\section{References}

1. Henley SJ, Anderson RN, Thomas CC, Massetti GM, Peaker B, Richardson LC. Invasive cancer incidence, 2004-2013, and deaths, 2006-2015, in nonmetropolitan and metropolitan counties-United States. MMWR Surveill Summ 2017;66:1-13.

2. Fischer B, Anderson S, Bryant J, et al. Twenty-year follow-up of a randomized trial comparing total for the treatment of invasive breast cancer. New English J Med 2002;347:1233-1241.

3. Veronesi U, Cascinelli N, Mariani L, et al. Twenty-year follow-up of a randomized study comparing breast-conserving surgery with radical mastectomy for early breast cancer. N Engl J Med 2002;347:1227-1232.

4. Abe $\mathrm{O}$, Abe R, Enomoto $\mathrm{K}$, et al. Effects of radiotherapy and of differences in the extent of surgery for early breast cancer on local recurrence and 15year survival: An overview of the randomised trials. Lancet 2005;366 2087-2106.

5. Dragun AE, Huang B, Tucker TC, Spanos WJ. Disparities in the application of adjuvant radiotherapy after breast-conserving surgery for early stage breast cancer. Cancer 2011;117:2590-2598.

6. Smith BD, Jiang J, Shih YC, et al. Cost and complications of local therapies for early-stage breast cancer. J Natl Cancer Inst 2017;109:djw178.

7. Moyer A. Psychosocial outcomes of breast-conserving surgery versus mastectomy: A meta-analytic review. Cancer patients their Fam Readings Dis course, coping. Psychol Interv 1997;16:259-288.

8. Nattinger AB, Hoffmann RG, Kneusel RT, Schapira MM. Relation between appropriateness of primary therapy for early-stage breast carcinoma and increased use of breast-conserving surgery. Lancet 2000;356: 1148-1153.

9. Freedman RA, He Y, Winer EP, Keating NL. Trends in racial and age disparities in definitive local therapy of early-stage breast cancer. J Clin Oncol 2009;27:713-719.

10. Hershman DL, Buono D, McBride RB, et al. Surgeon characteristics and receipt of adjuvant radiotherapy in women with breast cancer. J Natl Cancer Inst 2008;100:199-206.

11. Gold HT, Do HT, Dick AW. Correlates and effect of suboptimal radiotherapy in women with ductal carcinoma in situ or early invasive breast cancer. Cancer 2008;113:3108-3115.

12. Ulcickas Yood M, Owusu C, Buist DSM, et al. Mortality impact of less-thanstandard therapy in older breast cancer patients. J Am Coll Surg 2008;206: 66-75.

13. Whelan T. Randomized trial of breast irradiation schedules after lumpectomy for women with lymph node-negative breast cancer. CancerSpectrum Knowl Environ 2002;94:1143-1150.

14. Athas WF, Adams-Cameron M, Hunt WC, Amir-Fazli A, Key CR. Travel distance to radiotherapy and receipt of radiotherapy following breastconserving surgery. J Natl Cancer Inst 2000;92:269-271.

15. Meden T, St. John-Larkin C, Hermes D SS. Relationship between travel distance and utilization of breast cancer treatment in rural northern Michigan. JAMA 2002;287:111.

16. Schroen AT, Brenin DR, Kelly MD, Knaus WA, Slingluff CL. Impact of patient distance to radiation therapy on mastectomy use in early-stage breast cancer patients. J Clin Oncol 2005;23:7074-7080.

17. Celaya MO, Rees JR, Gibson JJ, Riddle BL, Greenberg ER. Travel distance and season of diagnosis affect treatment choices for women with early- stage breast cancer in a predominantly rural population (United States). Cancer Causes Control 2006;17:851-856.

18. Voti L, Richardson LC, Reis IM, Fleming LE, MacKinnon J, Coebergh JWW. Treatment of local breast carcinoma in Florida: The role of the distance to radiation therapy facilities. Cancer 2006;106:201-207.

19. Lin Y, Wimberly MC, Da Rosa P, Hoover J, Athas WF. Geographic access to radiation therapy facilities and disparities of early-stage breast cancer treatment. Geospat Health 2018;13:93-101.

20. Boscoe FP, Johnson CJ, Henry KA, et al. Geographic proximity to treatment for early stage breast cancer and likelihood of mastectomy. Breast 2011;20:324-328.

21. Nattinger $A B$, Ronald T, Hoffmann RG, Gilligan M. Relationship of distance from a breast cancer treatment. J Natl Cancer Inst 2001;93:1344-1346.

22. Churilla TM, Donnelly PE, Leatherman ER, Adonizio CS, Peters CA. Total mastectomy or breast conservation therapy? how radiation oncologist accessibility determines treatment choice and quality: A SEER data-base analysis. Breast J 2015;21:473-480.

23. Wheeler SB, Kuo T, Durham D, Frizzelle B, Reeder-Hayes K, Meyer A. Effects of distance to care and rural or urban residence on receipt of radiation therapy breast cancer among North Carolina Medicare Enrollees with Breast Cancer. N C Med J 2014;75:239-246.

24. National Cancer Institute Division of Cancer Control \& Population Healthcare Delivery Research Program. SEER-Medicare Database. Available at: https://healthcaredelivery.cancer.gov/seermedicare/overview Accessed March 31, 2020.

25. Duggan MA, Anderson WF, Altekruse S, Penberthy L, Sherman ME. The surveillance, epidemiology, and end results (SEER) program and pathology: Toward strengthening the critical relationship. Am J Surg Pathol 2016;40:e94-e102.

26. National Cancer Institute Division of Cancer Control \& Population Sciences. SEER-Medicare: Selecting the Appropriate Comorbidity SAS Macro. Available at: https://healthcaredelivery.cancer.gov/seermedicare/ considerations/calculation.html Accessed February 1, 2019.

27. Nattinger AB, Laud PW, Bajorunaite R, Sparapani RA, Freeman JL. An algorithm for the use of medicare claims data to identify women with incident breast cancer. Health Serv Res 2004;39(6p1):1733-1750.

28. Srokowski T, Fang S, Duan Z, et al. Completion of adjuvant radiation therapy among women with breast cancer. Cancer 2008;113:22-29.

29. Swanick CW, Lei X, Shaitelman SF, et al. Longitudinal analysis of patientreported outcomes and cosmesis in a randomized trial of conventionally fractionated versus hypofractionated whole-breast irradiation. Cancer 2016;122:2886-2894.

30. ESRI 2018. ArcGIS Pro: Version 10.6.1. Redlands, CA: Environmental Systems Research Institute. Release Date: July 2018.

31. Google Web Services. Distance Matrix API. Available at: https://developers .google.com/maps/documentation/distance-matrix/intro Accessed March 31, 2020

32. Brooks JM, Chrischilles EA, Landrum MB, et al. Survival implications associated with variation in mastectomy rates for early-staged breast cancer. Int J Surg Oncol. 2012;2012:127854.

33. Hausman JA, McFadden D. Specification tests for the Multinomial Logit Model. Econometrica 1984;52:1219-1240.

34. McFadden D. Econometric models of probabilistic choice. In: Manski CF, McFadden DL, eds. Structural analysis of discrete data and econometric applications. Cambridge, MA: MIT Press, 1981:198-272.

35. Hilmer MJ. A comparison of alternative specifications of the college attendance equation with an extension to two-stage selectivity-correction models. Econ Educ Rev 2002;20:263-278.

36. Hughes KS, Schnaper LA, Bellon JR, et al. Lumpectomy plus tamoxifen with or without irradiation in women age 70 years or older with early breast cancer: Long-term follow-up of CALGB 9343. J Clin Oncol 2013;31:2382-2387.

37. Gradishar WJ, Anderson BO, Balassanian R, et al. Clinical practice guidelines in oncology. JNCCN J Natl Compr Cancer Netw 2018;16:310-320.

38. Baldwin LM, Patel S, Andrilla CHA, Rosenblatt RA, Doescher MP. Receipt of recommended radiation therapy among rural and urban cancer patients Cancer 2012;118:5100-5109.

39. Punglia RS, Weeks JC, Neville BA, Earle CC. Effect of distance to radiation treatment facility on use of radiation therapy after mastectomy in elderly women. Int J Radiat Oncol Biol Phys 2006;66:56-63.

40. Ambroggi M, Biasini C, Del Giovane C, Fornari F, Cavanna L. Distance as a barrier to cancer diagnosis and treatment: Review of the literature. Oncologist 2015;20:1378-1385. 
41. Charlton M, Schlichting J, Chioeso C, Ward M, Vikas P. Challenges of rural cancer care in the United States. Oncol J 2015;29:633-640.

42. Longacre CF, Neprash HT, Shippee ND, Tuttle TM, Virnig BA. Evaluating travel distance to radiation facilities among rural and urban breast cancer patients in the Medicare Population. J Rural Health 2020;36:334-346.

43. Unger JM, Moseley A, Symington B, Chavez-MacGregor M, Ramsey SD, Hershman DL. Geographic distribution and survival outcomes for rural patients with cancer treated in clinical trials. JAMA Netw Open 2018;1: e181235.

44. Smith G, Xu Y, Buchholz TA, Giordano SH, Jiang J, Shih YC. Association between treatment with brachytherapy vs whole-breast irradiation and subsequent mastectomy, complications, and survival among older women with invasive breast cancer. J Am Med Assoc 2012;307:18271837.

45. Martinez KA, Kurian AW, Hawley ST, Jagsi R. How can we best respect patient autonomy in breast cancer treatment decisions? Breast Cancer Manag 2015;4:53-64.

46. Emanuel EJ. Four models of the physician-patient relationship. J Am Med Assoc 1992;267:2221-2226.

47. Brown $\mathrm{P}$, Elston MA, Gabe J. From patient deference towards negotiated and precarious informality: An Eliasian analysis of English general practitioners' understandings of changing patient relations. Soc Sci Med 2015 146(May 1999):164-172.

48. Lantz P, Janz N, Fagerlin A, et al. Satisfaction with surgery outcomes and the decision process in a population-based sample of women with breast cancer. Health Serv Res 2005;40:745-767.

49. Sepucha KR, Fowler FJ, Mulley AG. Policy support for patient-centered care: The need for measurable improvements in decision quality. Health Aff (Millwood) 2004:23(SUPPL):VAR54-62.

50. Charles C, Gafni A, Whelan T. Self-reported use of shared decision-making among breast cancer specialists and perceived barriers and facilitators to implementing this approach. Heal Expect 2004;7:338-348.

51. Obeidat R, Finnell DS, Lally RM. Decision aids for surgical treatment of early stage breast cancer: A narrative review of the literature. Patient Educ Couns 2011;85:e311-e321.

52. Whelan $T$, Levine $M$, Sanders $K$, et al. Effect of a decision aid on knowledge and treatment decision making for breast cancer surgery. JAMA 2012;292:435-441.

53. Sanghani M, Truong PT, Raad RA, et al. Validation of a web-based predictive nomogram for ipsilateral breast tumor recurrence after breast conserving therapy. J Clin Oncol 2010;28:718-722.

54. Jagsi R, Abrahamse $P$, Morrow M, et al. Patterns and correlates of adjuvant radiotherapy receipt after lumpectomy and after mastectomy for breast cancer. J Clin Oncol 2010;28:2396-2403.

55. Zhou J, Griffith KA, Hawley ST, et al. Surgeons' knowledge and practices regarding the role of radiation therapy in breast cancer management. Radiat Oncol Biol 2013;87:1022-1029.

56. The START Trialist Group. The UK Standardisation of Breast Radiotherapy (START) Trial A of radiotherapy hypofractionation for treatment of early breast cancer: A randomised trial. Lancet Onocol 2008:9:331-341.

57. Smith BD, Arthur DW, Buchholz TA, et al. Accelerated Partial Breast Irradiation Consensus Statement From the American Society for Radiation Oncology (ASTRO). Int J Radiat Oncol Biol Phys 2009;74:987-1001.
58. Jagsi R, Falchook AD, Hendrix LH, Curry H, Chen RC. Adoption of hypofractionated radiation therapy for breast cancer after publication of randomized trials. Int J Radiat Oncol Biol Phys 2014;90:1001-1009.

59. Mccormick B, Ottesen RA, Hughes ME, et al. Impact of guideline changes on use or omission of radiation in the elderly with early breast cancer: Practice patterns at National Comprehensive Cancer Network Institutions. J Am Coll Surg 2014;219:796-802.

60. Soulos PR, Yu JB, Roberts KB, et al. Assessing the impact of a Cooperative Group Trial on Breast Cancer Care in the medicare population. J Clin Oncol 2012;30:1601-1607.

61. Jacobson M, Earle CC, Price M, Newhouse JP. How medicare's payment cuts for cancer chemotherapy drugs changed patterns of treatment. Health Aff (Millwood) 2010;29:1391-1399.

62. Hannoun-Lévi JM, Cham Kee DL, Gal J, et al. Accelerated partial breast irradiation for suitable elderly women using a single fraction of multicatheter interstitial high-dose-rate brachytherapy: Early results of the Single-Fraction Elderly Breast Irradiation (SiFEBI) Phase I/II trial. Brachytherapy 2018;17:407-414.

63. Hope Lodges. American Cancer Society. Available at: https://www.cancer .org/content/cancer/en/treatment/support-programs-and-services/patientlodging/hope-lodge.html. Published 2019. Accessed March 21, 2019.

64. Road to Recovery. American Cancer Society. Available at: https://www .cancer.org/treatment/support-programs-and-services/road-to-recovery .html. Published 2019. Accessed March 21, 2019.

65. Chaiyachati KH, Hubbard RA, Yeager A, et al. Rideshare-Based Medical Transportation for Medicaid Patients and Primary Care Show Rates: A Difference-in-Difference Analysis of a Pilot Program. J Gen Intern Med 2018;33:863-868.

66. Chaiyachati $\mathrm{KH}$, Moore K, Adelberg M. Too early to cut transportation benefits from Medicaid Enrollees. Heal Serv Insights 2018;12: 117863291880481.

Cite this article as: Longacre CF, Neprash $\mathrm{HT}$, Shippee ND, Tuttle TM, Virnig BA (2021) Travel, treatment choice, and survival among breast cancer patients: A population-based analysis, Women's Health Report 2:1, 1-10, DOl: 10.1089/whr.2020.0094.

$\begin{aligned} & \text { Abbreviations Used } \\ & \mathrm{BCS}=\text { breast-conserving surgery } \\ & \mathrm{Cl}=\text { confidence interval } \\ & \mathrm{FFS}=\text { fee-for-service } \\ & \mathrm{HR}=\text { hazards ratio } \\ & \mathrm{IMRT}=\text { intensity-modulated radiation therapy } \\ & \mathrm{NCl}=\text { National Cancer Institute } \\ & \mathrm{OR}=\text { odds ratio } \\ & \mathrm{RT}=\text { radiation therapy } \\ & \mathrm{SEER}=\text { Surveillance Epidemiology and End Results }\end{aligned}$

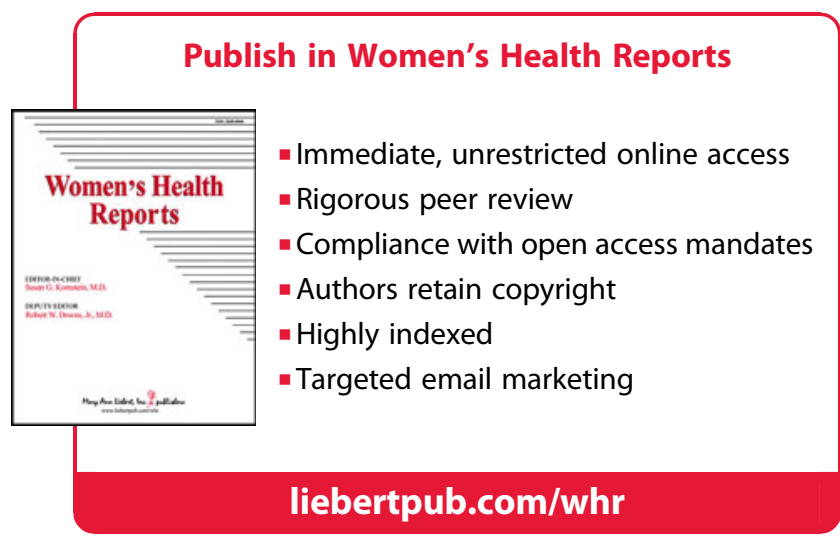

